\title{
Split Phase SPIM Characteristics Optimization using PSO Algorithm
}

\author{
M.A.Taghikhani
}

Department of Engineering, Imam Khomeini International University, Qazvin, Iran taghikhani@ikiu.ac.ir

\begin{abstract}
The application of particle swarm optimization (PSO) in parameters design of a split-phase single-phase induction motor is proposed in this paper. The PSO considers the motor efficiency as objective function and five performance related items as constraints. The main advantages of the proposed technique are; its simple structure and its straightforward verification of maximum efficiency of induction motor for a given output power. The PSO algorithm was implemented on a test motor and therefore, a code has been provided under MATLAB software. The results show that the PSO method gives more suitable design optimization against conventional methods.
\end{abstract}

Keywords Design Optimization; Single Phase Induction Motor (SPIM); Maximum Efficiency; Particle Swarm Optimization (PSO)

\section{Introduction}

Presently, millions of SPIMs in smaller sizes are in the commercial and domestic field. Therefore, even a minor improvement in the design of this kind of motors may save a vast electrical energy worldwide[1]. There are many types of SPIMs, depending upon the starting arrangement provided with the motor. Advances in the design of these motors have made an improvement in the power factor and efficiency of the motor. Split-phase, capacitor-start, shaded-pole and repulsion-type motors are quite popular from industrial viewpoint. Split phase single phase induction motor design is studied in this paper.

A number of works have reported the improvement of SPIMs efficiency so far. Active power loss effect in induction motor optimum design has proposed in[2]. The method of boundary search along active constraints and the Han-Powell method for optimization of single phase induction motor design have been presented in[3,4]. A triac-based drive with an optimal efficiency voltage controller is proposed in[5]. An appropriate method for motor efficiency maximization control, combined with a variable-speed drive, has been presented in[6]. Electrical machine design optimization using genetic algorithm has discussed in[7]. Some of the evolutionary algorithms for optimal design are available in the literatures[8-11].

This paper proposes a method for design optimization of

* Corresponding author:

taghikhani@ikiu.ac.ir (M.A.Taghikhani)

Published online at http://journal.sapub.org/ijea

Copyright $(2012$ Scientific \& Academic Publishing. All Rights Reserved single-phase induction motor to maximize the efficiency using particle swarm optimization (PSO). The present paper will be organized as follows. Section 2 briefly explains PSO algorithm. Section 3 presents relationships governing single-phase induction motor. Section 4 discusses the optimal design with variables and constraints. Section 5 gives the detailed discussion on the results of PSO algorithm and their comparison with conventional design.

\section{Particle Swarm Optimization}

PSO is a population-based, stochastic optimization algorithm based on the idea of a swarm moving over a given landscape. The algorithm adaptively updates the velocities and members positions of the swarm by learning from the good experiences. In PSO, the velocity $v_{i}^{d}$ and position $x_{i}^{d}$ of the $d$ th dimension of the $i$ th particle are updated as follows:

$$
\begin{gathered}
v_{i}^{d}=w \cdot v_{i}^{d}+c_{1} \cdot r_{1} \cdot\left(\text { pbest }_{i}^{d}-x_{i}^{d}\right)+c_{2} \cdot r_{2} \cdot\left(\text { gbest }^{d}-x_{i}^{d}\right) \\
x_{i}^{d}=x_{i}^{d}+v_{i}^{d}
\end{gathered}
$$

Where

$x_{i}$ :the position of the ith particle

$v_{i}$ : the velocity of particle $i$

pbest $t_{i}$ :the best location in the search space ever visited by particle $i$

gbest : the best location discovered so far

$w$ : the inertia weight that controls the impact of previous velocity of particle on its current one

$r_{1}, r_{2}$ : independently uniformly distributed random variables with range $(0,1)$

$c_{1}, c_{2}$ : positive constants(acceleration) coefficients which control the maximum step size. 
In PSO, equation (1) is used to calculate the new velocity according to its previous velocity and to the distance of its current position from both its own best historical position and the best position of the entire population or its neighbourhood. Generally, the value of each component in $v$ can be clamped to the range $\left[-v_{\max }, v_{\max }\right]$ to control excessive roaming of particles outside the search space. Then the particle flies toward a new position according equation (2). This process is repeated until a user-defined stopping criterion is reached. A linearly decreasing inertia weight from maximum value $w_{\max }$ to minimum value $w_{\min }$ is used to update the inertia weight:

$$
w^{k}=w_{\max }-\frac{w_{\max }-w_{\min }}{k_{\max }} \cdot k
$$

$K_{\max }$ is maximum iteration number[12,13].

\section{Relationships Governing Single Phase Induction Motor}

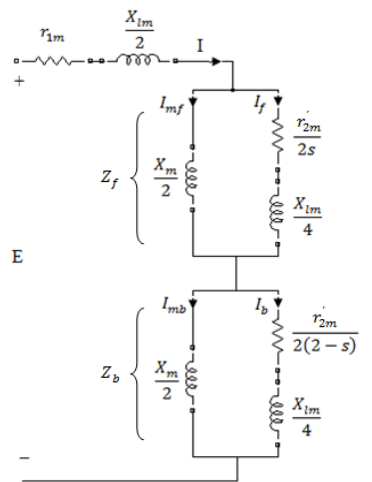

Figure.1. equivalent circuit of SPIM based on double revolving field theory

Like other types of electrical machines, SPIMs are also designed to meet a given set of specifications. The motor has to be designed to give sufficient starting torque with reasonable performance during its working period. Fig. 1 illustrates equivalent circuit of SPIM based on double rotating field theory. The power flow diagram for a SPIM is shown in Fig. 2. Considering figures 1 and 2 relationships governing single phase induction motor may be expressed as follows[1]:

$$
\begin{gathered}
r_{1 m}=\frac{\rho \cdot l_{m t m} \cdot T_{m}}{a_{m}} \\
a_{m}=\pi \cdot \frac{d_{m}^{2}}{4} \\
r_{1 a}=\frac{\rho \cdot l_{m t a} \cdot T_{a}}{a_{a}} \\
a_{a}=\pi \cdot \frac{d_{a}{ }^{2}}{4} \\
r_{2 m}^{\prime}=2 \cdot N_{m}{ }^{2} \cdot K_{w m}{ }^{2} \cdot \rho \cdot\left[\frac{l_{b}}{A_{b} \cdot N_{b}}+\frac{0.64 \cdot D_{m}}{P^{2} \cdot A_{e}}\right] \\
X_{l m}=X_{s}+X_{z z}+X_{e}+X_{b}+X_{s k} \\
X_{m}=K_{x} \cdot\left(0.2546 \cdot K_{m} \cdot C_{s k}\right)
\end{gathered}
$$

$$
\begin{gathered}
K_{x}=2 \cdot \pi \cdot f \cdot\left(N_{m} \cdot K_{w m}\right)^{2} \cdot 10^{-8} \\
k_{m}=\frac{\pi \cdot D_{i} \cdot L / 2}{l_{g}^{\prime} \cdot S_{f} \cdot P} \\
C_{s k}=\frac{\sin (\alpha / 2)}{\frac{\pi \cdot \alpha}{360}}
\end{gathered}
$$

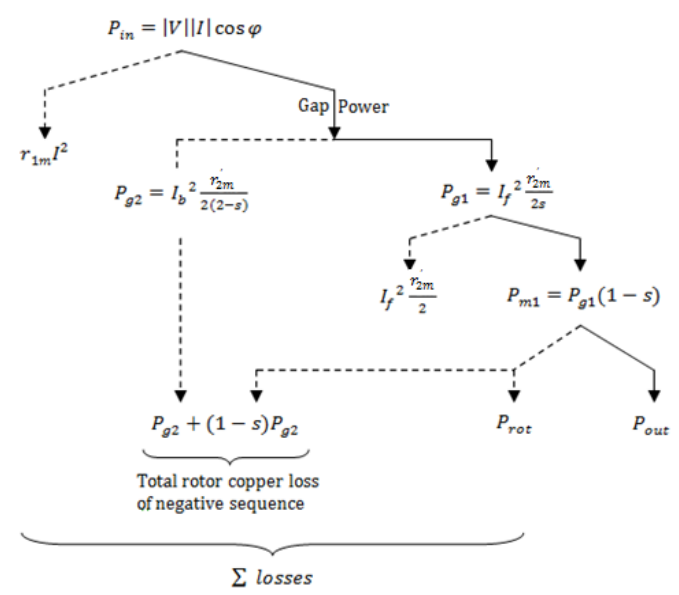

Figure.2. power flow diagram for a SPIM

$$
\begin{gathered}
Z_{f}=\frac{\left(j \frac{X_{m}}{2}\right)\left(\frac{r_{2 m}^{\prime}}{2 s}+j \frac{X_{\text {lm }}}{4}\right)}{\frac{r_{2 m}^{\prime}}{2 s}+j\left(\frac{X_{l m}}{4}+\frac{X_{m}}{2}\right)} \\
Z_{b}=\frac{\left(j \frac{X_{m}}{2}\right)\left(\frac{r_{2 m}^{\prime}}{2(2-s)}+j \frac{X_{\text {lm }}}{4}\right)}{\frac{r_{2 m}^{\prime}}{2(2-s)}+j\left(\frac{X_{\text {lm }}}{4}+\frac{X_{m}}{2}\right)} \\
Z_{\text {total }}=r_{1 m}+j \frac{X_{\text {lm }}}{2}+Z_{f}+Z_{b} \\
I=\frac{V}{Z_{\text {total }}}=|I| \angle \varphi \\
P f=\cos \varphi \\
P_{\text {in }}=|V| I \mid \cos \varphi \\
P_{\text {out }}=P_{m 1}-P_{\text {rot }}-(1-s) P_{g 2} \\
\eta=\frac{P_{\text {out }}}{P_{\text {in }}}
\end{gathered}
$$

Where:

$r_{l m}, r_{l a}$ : Stator resistances of main and auxiliary winding, respectively

$a_{m}, a_{a}$ : Area of the main and auxiliary winding conductor, respectively

$d_{m}, d_{a}$ : Wire diameter of main and auxiliary winding, respectively

$T_{m}, T_{a}$ : Number of turns in main and auxiliary winding, respectively

$\dot{r}_{2 m}:$ Rotor resistance

$X_{l m}$ : Leakage reactance

$X_{m}$ : Magnetizing reactance

$X_{S}$ : Slot leakage reactance

$X_{z z}$ : Zig zag leakage reactance

$X_{e}$ : End leakage reactance

$X_{b}$ : Belt leakage reactance

$X_{s k}$ : Skew leakage reactance 
$D_{i}:$ Stator bore diameter

$L$ : Stator stack length

$P$ : Number of poles

$V$ : Voltage

$I$ : Current in main winding

$f$ : Frequency

$s$ : Rotor slip

Pf: Power Factor

$K_{w m}$ : Winding factor

$\alpha$ : Skew of rotor

$\rho$ : Copper resistivity

$S_{1}$ : Number of stator slots

$S_{2}$ : Number of rotor slots

$l_{m t m}$ : Length of mean turn of the main winding

$l_{m t a}$ : Length of mean turn of the auxiliary winding

$N_{m}$ : Number of conductors in stator main winding

$l_{b}$ : Length of rotor bar

$l_{g}$ : Effective gap length

$A_{e}$ : Area of the end ring

$S_{f}$ : Saturation factor

$D_{m}$ : Mean diameter of rotor

$N_{b}$ : Number of rotor bars

$A_{b}$ : Area of the rotor conductor

$P_{\text {in }}$ : Input power

$P_{\text {out }}:$ Output power

$\eta$ : Efficiency

\section{Optimal SPIM Design}

The first optimization component is usually formulated is minimizing $f(x)$ such that $x$ exists within the $\mathrm{n}$-dimensional feasible region $D=\left\{x \mid x \geq 0, g_{i}(x) \leq 0, i=1,2, \ldots, m\right\} . f(x), g_{i}(x)$ are real-valued scalar functions and vector $x$ includes the $n$ principal variables for which the optimization is to be performed. The function $f(x)$ is called the "objective function", for which the optimal values of $x$ result in the minimum (maximum) of $f(x)$, and these optimal values satisfy the given constraints. Inequality constraints $g_{i}(x) \leq 0$ include the performance properties of the motor, dimensional restrictions and additional requirements[3]. The following variables $\left(x_{1} \ldots x_{6}\right)$ are considered as the principal or independent variables of optimization:

$x_{1}$ : Stator bore diameter $(\mathrm{m})$

$x_{2}$ : Stator stack length $(\mathrm{m})$

$x_{3}$ : Number of turns in main winding

$x_{4}$ : Number of turns in auxiliary winding

$x_{5}$ : Wire diameter of main winding $(\mathrm{mm})$

$x_{6}$ : Wire diameter of auxiliary winding $(\mathrm{mm})$

The performance constraints imposed into induction motor design in this paper is as follows which are expressed in terms of variables:

1. Power factor at rated load

2. Locked rotor current to rated current ratio

3. Starting torque to full load torque ratio

4. Current density in the main winding

5. Current density in the auxiliary winding
The motor efficiency $\eta$ has been taken as objective function to be maximized.

\section{Results and Discussions}

The PSO algorithm is implemented to optimize the design of induction motor whose specifications are available in appendix. Results are compared with conventional design and tabulated in table 1 . It is observed from the table that the efficiency of the induction motor has increased using PSO compared to the conventional design. Full load slip in PSO is smaller than conventional design. Starting torque to full load torque ratio is slightly better than the other. The PSO algorithm parameters used in this paper are tabulated in table 2 which determined by trial and error method by using computer simulations. Fig. 3 shows the variations of efficiency against the PSO iteration number during the optimization process. The variations of motor efficiency verse the output power and rotor slip are shown in figures 4 and 5, respectively. From figures 4 and 5 , it is obvious that maximum efficiency is achieved at the rated output power with rotor slip of 0.0332 .

Table 1. Results of conventional and PSO based induction motor design

\begin{tabular}{|c|c|c|}
\hline Motor Parameters & Conventional design & PSO algorithm \\
\hline Stator bore diameter $(\mathrm{m})$ & 0.1 & 0.11227 \\
\hline Stator stack length (m) & 0.06 & 0.045 \\
\hline $\begin{array}{l}\text { Number of turns in main } \\
\text { winding }\end{array}$ & 184 & 206 \\
\hline $\begin{array}{l}\text { Number of turns in aux- } \\
\text { iliary winding }\end{array}$ & 262 & 270 \\
\hline $\begin{array}{l}\text { Wire diameter of main } \\
\text { winding }(\mathrm{mm})\end{array}$ & 1.42 & 1.4381 \\
\hline $\begin{array}{l}\text { Wire diameter of auxil- } \\
\text { iary winding ( } \mathrm{mm})\end{array}$ & 0.711 & 0.7377 \\
\hline Efficiency $(\%)$ & 0.7859 & 0.8053 \\
\hline Power factor & 0.8324 & 0.8324 \\
\hline $\begin{array}{l}\text { Starting torque to full load } \\
\text { torque ratio }\end{array}$ & 0.7570 & 0.7576 \\
\hline Full load slip & 0.0366 & 0.0332 \\
\hline
\end{tabular}

Table 2. Parameters of the PSO

\begin{tabular}{cc}
\hline Parameters & Value \\
\hline Population size & 100 \\
dimension number & 6 \\
Max iteration & 200 \\
$w_{\max }$ & 0.9 \\
$w_{\min }$ & 0.4 \\
$c_{1}$ & 2 \\
$c_{2}$ & 2 \\
\hline
\end{tabular}

\section{Conclusions}

The application of particle swarm optimization (PSO) in parameters design of a split-phase single-phase induction motor is investigated in this paper. The induction motor design optimization is formulated as a nonlinear programming problem and the motor efficiency is considered as objective function. . It was observed that the efficiency of the 
induction motor was increased using PSO compared to the conventional design and full load slip in PSO was smaller than conventional design. The main advantages of the proposed technique are; its simple structure and its straightforward verification of maximum efficiency of induction motor for a given output power. The PSO offered better results compared with conventional design and it is more suitable to design optimization of single phase induction motor.

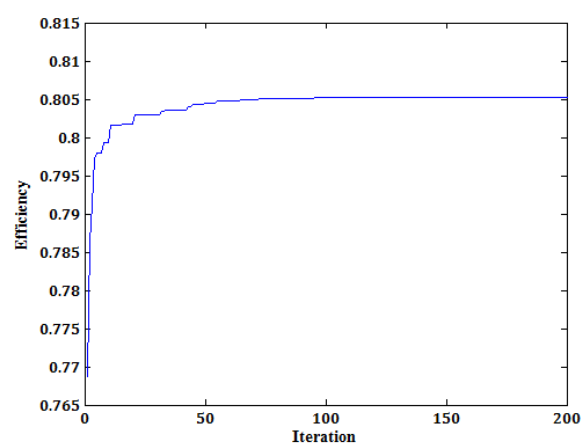

Figure 3. Variation of efficiency against PSO iteration number

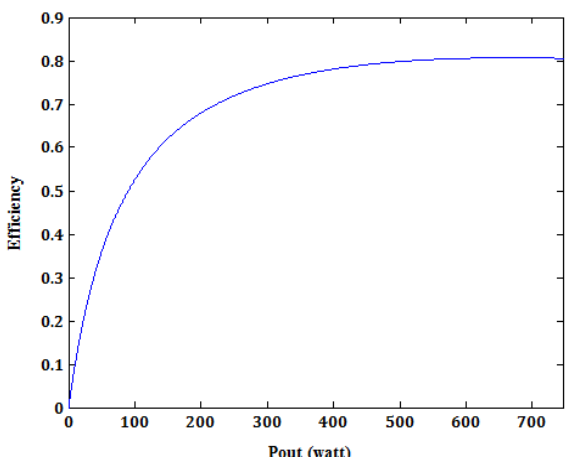

Figure 4. Variation of designed motor efficiency against output power

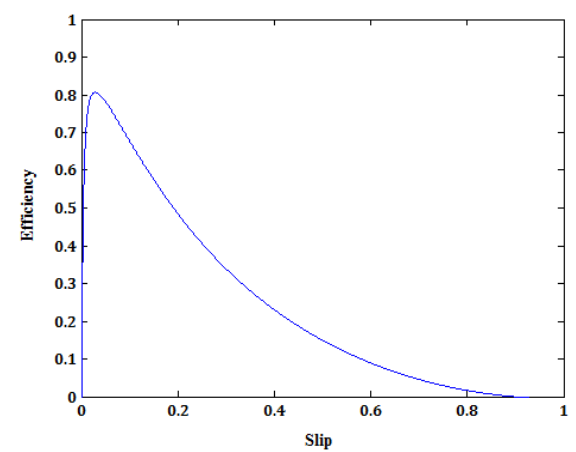

Figure 5. Variation of motor efficiency against rotor slip

\section{Appendix}

Specifications of SPIM motor:

$\begin{array}{lc}\text { Capacity } & 1 \mathrm{hp} \\ \text { Voltage } & 115 \mathrm{~V} \\ \text { Frequency } & 50 \mathrm{~Hz} \\ \text { Number of poles } & 2 \\ \text { Number of stator slots } & 24\end{array}$

\section{REFERENCES}

[1] Mittle V.N., Mittal A.; "Design of electrical machines", Fourth editions, Standard Publishers Distributors, 1996.

[2] Fetih N.H., EI-Shewy H.M.; "Induction motor optimum design, including active power loss effect", IEEE Transactions on Energy Conversion, 1986, Vol. 1, No. 3, pp. 155-160.

[3] Huang H., Fuchs E.F., Zak Z.; “'Optimization of single-phase induction motor design, I: Formulation of the optimization technique", IEEE Transactions on Energy Conversion, 1988, Vol. 3, No. 2, pp. 349-356.

[4] Huang H., Fuchs E.F., White J.C.; "Optimization of single-phase induction motor design, II: The maximum efficiency and minimum cost of an optimal design", IEEE Transactions on Energy Conversion, 1988, Vol. 3, No. 2, pp. 357-366.

[5] Mademlis C., Kioskeridis I., Theodoulidis T.; "Optimization of single-phase induction motors Part I: Maximum energy efficiency control", IEEE Transactions on Energy Conversion, 2005, Vol. 20, No. 1, pp. 187-195.

[6] Zahedi B., Vaez-Zadeh S.; "Efficiency optimization control of single-phase induction motor drives", IEEE Transactions on Power Electronics, 2009, Vol. 24, No. 4, pp. 1062-1070.

[7] Uler G.F., Mohammed O.A., and Chang-Seop Koh; "Design optimization of electrical machines using genetic algorithms", IEEE Transactions on Magnetics, 1995, Vol. 31, No. 3, pp. 2008-2011.

[8] Wieczorek J.P., Gol O., Michalewicz Z.; “An evolutionary algorithm for the optimal design of induction motors", IEEE Transactions on Magnetics, 1998, Vol. 34, No. 6, pp. 3882 3887.

[9] Bhuvaneswari R., Subramanian S.; "Optimization of single-phase induction motor design using radial basis function network", IEEE Indicon Conference, Chennai, India, pp. 35-40, 11-13 Dec. 2005.

[10] Bellarmine G.T., Bhuvaneswari R., Subramanian S.; "Radial basis function network based design optimization of induction motor", Proceedings of the IEEE Southeast Conference, pp. 75-80, 2006.

[11] Raj C.T., Srivastava S. P. Agarwal P.; "Realization on PSO based induction motor design via SPEED/PC-IMD", International Conference on Advanced Computer Control(ICACC'09), pp. 65-69, 2009.

[12] Wang Y., Li B., Weise T., Wang J., Yuan B., Tian Q.; "Self-adaptive learning based particle swarm optimization", Information Sciences, 2011, Vol.181, No.20, pp. 4515-4538.

[13] Jiang Y., Hu T., Huang C., Wu X.; “An improved particle swarm optimization algorithm", Applied Mathematics and Computation, 2007, Vol. 193, No.1, pp. 231-239. 